\title{
Exploring Middle Class Pentecostalism in Argentina - Methodological Considerations
}

The objective of this study is to explore middle class Pentecostalism in Argentina. The central questions that guide the research include the following: In what kind of socio-cultural context is middle class Pentecostalism embedded? How does the middle class relate to Pentecostalism? What form of Pentecostalism do middle class Pentecostals develop?

Therefore, this study places an emphasis on middle class Pentecostals and above all on Pentecostals who work as professionals and hold higher education degrees. Argentina and Buenos Aires in particular were purposefully chosen for the research since they lend themselves for the study of middle class Pentecostalism. ${ }^{1}$ Most importantly, Argentina has the reputation of being one of the countries with the strongest middle class in Latin America. ${ }^{2}$ The presence of an extensive middle class was thought to facilitate the study of middle class Pentecostalism. Especially Buenos Aires is known for its relatively wealthy middle class population. At the same time Buenos Aires is marked by the presence of slums in the city and a bolster of lower class neighborhoods and slums surrounding the city. Shaped by strong social inequalities, Buenos Aires lends itself to studying the reproduction of inequalities within the field of religion. Another reason for choosing Argentina was the comparatively late mass expansion of the Pentecostal movement in this country. In contrast to other countries where the Pentecostal movement grew massively from the 1950s onwards, Argentina experienced a rather late mass expansion of Pentecostalism starting in the late 1980 s and the beginning of the 1990s. Due to the late expansion of Pentecostalism, the vast majority of actors who participate today in Pentecostal churches were not born in into their church but chose at one point in their lives to affiliate with a particular Pentecostal church. Furthermore, it can be assumed that when they chose to affiliate themselves with a specific Pentecostal church, they decided upon a specific style of Pentecostalism.

1 The aim of purposeful sampling is to select an information-rich case with regard to the research question (Patton 1990: 169). Pentecostalism in Buenos Aires meets this criterion.

2 Tevik 2006: 23-24; Visacovsky 2008: 11-12. The rise of the middle class in Argentina was prominently studied by Argentinean sociologist Gino Germani. For the expansion of the middle class in Argentina, see Germani 1950; 1966; 1981.

(C) JENS KOEHRSEN, 2016 | DOI 10.1163/9789004310148_004

This is an open access chapter distributed under the terms of the Creative Commons Attribution-

Noncommercial 3.o Unported (CC-BY-NC 3.0) License. 
Therefore, the study of the religious styles of churches and their social composition will allow for exploring the religious tendencies of different social classes in Pentecostalism.

My personal reasons for studying Pentecostalism in Latin America include a strong interest in the Pentecostal movement and a general interest for Latin American culture. I had my first contact with Pentecostalism in Germany. A friend who was a member of a Pentecostal congregation in my hometown took me on a Sunday morning to a church service. This experience and the following visits spurred my sociological interest in the Pentecostal movement. The interest in Pentecostalism combined with an affinity for some of Pierre Bourdieu's sociological concepts drove me to study the relationship between social class and Pentecostalism in Latin America.

Studying a religious movement in a foreign continent implies various difficulties. Although already fluent in Castellano - unfortunately the Spanish Castellano - I arrived as an outsider in Buenos Aires where I had to adapt my Spanish and to learn "how things work" in Argentina. This partial adaptation to the new situation did, of course, not change my general status as a stranger. My outsider status did, however, not only imply disadvantages. It also enriched my research to some extent. The lack of an Argentinean cultural background enabled me to observe my research object - middle class Pentecostalism - from a different, non-Argentinean angle. Moreover, being a stranger from a "respectable" European country, middle class, Pentecostals treated me usually with openness and welcomed me to their congregations.

\subsection{Methodical Remarks: Controlling the Quality of Qualitative Research}

The research bases itself on a combination of different research methods. This mixture of methods consists mainly of qualitative methods (ethnographic observation and in-depth interviews) and to a minor degree of quantitative methods (surveys). Qualitative research faces different challenges. Above all, qualitative research is marked by the fact that its explorations are based on a small number of cases. Therefore, qualitative research projects bear limitations regarding the generalizability of their results. ${ }^{3}$ A second problem, one related to the generalizability of qualitative research, addresses the credibility

3 Bryman 2008: 391-392; Gobo 2011: 29; Lamnek 2005: 180-187; Patton 1990: 486-49o. 
and reliability of the research results. ${ }^{4}$ Qualitative research runs the risk of being perceived as subjective since researchers may have a biasing impact on the research, which obtrudes the reproducibility of its results. ${ }^{5}$ I applied basically three strategies to avoid a subjective bias and to improve the credibility of the research: (1) orientation on methodological standards for qualitative research, (2) triangulation of methods and data sources, and (3) communicative validation.

The research was oriented along the common criteria for good qualitative research in data collection and analysis. These standards imply that the researcher seeks to adopt a stance of neutrality with regard to its research object. ${ }^{6}$ A strategy to increase the neutrality and credibility of one's research is triangulation which consists of the adoption of different perspectives on the research object. ${ }^{7}$ This study employs two types of triangulation: methods triangulation and triangulation of sources. Different methods were applied to gather data: participant observation, ethnographic interviews, narrative indepth interviews, quantitative surveys, and content-analyzes of existing studies. The employment of different methods implied also the exploration of different data sources: scientific studies and surveys, collective religious gatherings (church services), and interviews with pastors and church members. Another strategy to improve the credibility and neutrality of qualitative research is communicative validation. ${ }^{8}$ Communicative validation consists of providing accounts of one's research to peers and receiving a (critical) feedback. Similar to triangulation, this strategy can help assume different perspectives. During and after my empirical field research, I presented different parts of my project in numerous research seminars in Bielefeld, Oldenburg, Paris, and at various international conferences. On these occasions I received many comments and insights that allowed for controlling and improving the research approach.

4 Bryman 2008: 376-380; Heidenreich et al. 2012 46-48; Knoblauch 2003: 162-168; Patton 1990. Reliability and credibility concern the quality of the gathered data and the results drawn from it. In an objectified reading these criteria refer to the degree to which the data and results represent the given empirical reality while in a more constructivist reading the criteria refer to the degree to which the results will be accepted by scientific peers and/or the explored population as "correct".

5 Bryman 2008: 391; Gobo 2011: 28; Patton 1990: 54-56; 479-486.

6 Patton 1990: 461, 54-56.

7 Different perspectives can be adopted by combining different methods, data sources, or theories. See Bryman 2008: 377-379; Flick 2008; Lamnek 2005: 274-291; Patton 1990: 187-198, 464-470; Yin 2009: 114-118.

8 Knoblauch 2003: 166. 


\section{2} A Threefold Approach

The study of middle class Pentecostalism in Argentina was conceptualized as an explorative research project and was conducted on three empirical levels: macro, meso, and micro level. ${ }^{9}$ The macro level refers to the context of middle class Pentecostalism in Argentina and is based on an analysis of the existing literature about social class, religion in general, and Pentecostalism in particular. The actual empirical study was conducted on the meso and micro level. The meso level stresses religious organizations and explores the religious style of different Pentecostal churches while the micro level explores the religious tastes of Pentecostals from different social classes. The research was conducted in different waves between the second half of 2009 and the first half of 2011 . I spent a total of one and a half years in Buenos Aires, during which I assembled and studied the existing literature about the topic, conducted interviews and surveys, and visited a vast variety of Pentecostal churches. In the following paragraphs, I will present briefly the methods that I applied on each of the three levels.

The research on the macro-level included a study of the existing literature about social stratification, religion, and, more specifically, Pentecostalism in Argentina and Latin America. The aim was to generate an overview of the relationship between religious - and more particularly, Pentecostal - practice and social class. Of particular relevance for this process was the exploration of the existing literature about popular religion in Latin America and Argentina. While the religiosity and culture of Argentina's lower class is well studied, there is little literature about the culture of Argentina's urban middle class and virtually no literature about its religious tendencies. More developed is the research on Pentecostalism in Argentina. Thanks to the efforts of various local scholars - such as Joaquin Algranti, Alejandro Frigerio, Daniel Míguez, Hilario Wynarzcyk, and Pablo Semán - there exists today a variety of studies about Pentecostalism in Argentina. Yet, studies tackling the topic of Pentecostalism in the middle class do not exist thus far. Hence, I had to fill this gap with my own empirical research

Using the insights from the literature about social stratification, religion, and Pentecostalism in Argentina, I sought to sketch the context of middle class Pentecostalism: the historical development of the country, its social stratification, the symbolic class representations of the middle class,

9 A three level approach to study social groups which stress the macro, meso and micro level is, for instance, also proposed by Barth (1994: 20-30). 
the religious tendencies of the middle and lower class, and the tensions between Pentecostalism and middle class culture.

While the research on the macro-level intended to explore the broad context of middle class Pentecostalism, the actual empirical field work was conducted on the meso level and the micro level.

The objective of the research on the meso level was to identify potential peculiarities of Pentecostal churches that recruit a significant proportion of their membership from the middle class. To what style of Pentecostalism do middle class churches tend? What are the differences between middle class churches and other Pentecostal churches?

In order to determine the peculiarities of middle class churches, I compared the religious styles of churches which recruit their members from different social classes. The "religious style" is defined in a broad manner: the religious style of a church concerns all the characteristics that may potentially differ from that of other congregations and that may be relevant for members and potential members of the church. Therefore, the religious style embraces the style of church services as well as the physical infrastructure, organization, and symbolical recognition of the church. ${ }^{10}$

Although I visited a wide variety of churches with different social compositions, an emphasis was placed on churches that appealed the middle class. ${ }^{11}$ My empirical approach on the meso level entailed three steps: (1) visiting a wide range of different churches to explore the variety of Argentinean Pentecostalism, (2) limiting the study to a middle and a lower class church to explore their differences in a detailed manner, and (3) broadening my approach again by studying a sample of middle class churches and comparing it to the religious style of other Pentecostal churches. In the following paragraphs I describe these steps with more detail.

10 Also Meyer (2006) refers to the idea of religious style but uses the concept more in an aesthetic way. "Style is a core aspect of religious aesthetics (...). Inducing as well as expressing shared moods, a shared religious style - materializing in, for example, collective prayer, a shared corpus of songs, images, symbols, rituals, but also a similar clothing style and material culture - makes people feel at home." (Meyer 2006: 24) Another way of dealing with the religious style of a church is to describe it is a "congregational culture". Chaves (2004: 10) employs the term particularly with regard to different spheres of congregations: worship, education and the arts.

11 Moreover, my study focused on churches of a specific size: medium-sized churches. The focus on medium-sized churches is due to two reasons: (1) they are successful religious organizations which attract continuously a significant amount of members, and (2) they are more likely to show a relatively homogenous social composition in their membership than bigger churches which attract various social classes due to the fact that they usually embrace a variety of religious styles. 
In the first wave of research, I visited church services of a wide range of churches in the Argentinean capital and the province of Buenos Aires. This allowed me to get an overview of the Pentecostal movement and to develop some preliminary ideas about the relationship between social class and religious practice.

After having visited numerous Pentecostal church services in and around Buenos Aires, I limited my empirical research in a second step to a comparative case study of two Pentecostal churches. Although both churches are situated in middle class neighbourhoods, they recruit their members from different social classes. ${ }^{12}$ The pastors of both churches agreed to my project and supported my empirical research. This enabled me to conduct an extensive empirical research, including a quantitative survey, ethnographic observations, and narrative interviews. ${ }^{13}$ The quantitative survey explored the demographic composition of both congregations with a specific focus on the social backgrounds of church members. The surveys were conducted with the help of theology students from the Faculty for Protestant Theology in Buenos Aires, Instituto Superior Evangélico de Estudios Teológicos (ISEDET), during various weeks after different church services in the first half of the year 2009. ${ }^{14}$ Furthermore, I conducted narrative interviews with church members and pastors and participated in numerous churches services. After church services, I wrote field notes summarizing the structure, content, and environment of the church service, and other important impressions. ${ }^{15}$ Moreover, on many occasions I made audio-records of the church services and taped some parts of church services on video. The gathered data allowed me to create "thick descriptions" (Geertz 1973) of the religious style of each church and to compare them to each other. ${ }^{16}$ Constituting intensified studies of single units, ${ }^{17}$ the two case studies bear strong limits concerning their generalizability.

12 Both churches were purposefully selected since they show significant differences in their social composition. Thus, the sampling of these churches followed the strategy of a "maximum variation sampling" (Patton 1990: 172) in order to grasp the potential differences between lower and middle churches.

13 See for ethnographic - participant - observation Brymann 2008: 400-434, Diekmann 1995: 456-480; Flick 2002: 206-220; Knoblauch 2003 : 76-81; Lamnek 2005: 547-621.

14 The questionnaire was constructed along general criteria for designing questionnaires (cf. Diekmann 1995: 410-418). Moreover, two pretests were conducted in order to cut potential errors and improve the questionnaire.

15 For field research notes, see Knoblauch 2003: 90-96; Lamnek 2005: 613-621 Patton 1990: 239-244.

16 For ethnographic description, see Laplantine 2010.

17 A case study is an "intensive study of a single unit for the purpose of understanding a larger class of (similar) units." (Gerring 2004: 342). For case study research, see particularly Yin 2003. 
Although purposefully selected, the two cases form contingent cases that can hardly represent the whole population of lower and middle class churches in Buenos Aires. Therefore, I enlarged my sample in a third step and studied other churches that recruit a significant proportion of middle class Pentecostals in Buenos Aires. Yet, the number of medium-sized middle class churches appears to be highly limited in Buenos Aires. I detected a total of twelve middle churches in the area of Buenos Aires. ${ }^{18}$ In these churches, I conducted observations to determine potential differences and similarities in the religious style of middle churches and other Pentecostal churches that do not attract a significant number of middle class Argentineans. The most important form of exploration was the participation in the Sunday church services. Here, I observed the audience, the music, sermons, prayers and other activities during the church service. In many cases, I recorded short video and audio sequences of the central practices after getting permission from a church leader. Moreover, I conducted ethnographic interviews with members and ten narrative interviews with pastors. ${ }^{19}$ The interviews with the pastors entailed questions about the history and social composition of the church, church activities (groups, social projects etc.), practices during the church services, and their differences with regard to other Pentecostal churches. The study of a variety of churches allowed me to enlarge the empirical basis of the research. In total, the mesolevel research reveals how middle class Pentecostals draw boundaries in opposition to other Pentecostals by developing a distinctive style of Pentecostalism.

The objective of the research on the micro level was to study the way in which middle class Pentecostals draw boundaries by displaying specific religious tastes. The religious taste of middle class Pentecostals was analyzed by comparing it to the religious tastes of lower class Pentecostals. The religious taste of both groups - lower and middle class Pentecostals - was explored in qualitative, in-depth interviews. ${ }^{20}$ The central questions that guided this step of the research were: What are the religious tastes of educated middle class Pentecostals? How and with regard to what attributes do they draw boundaries when communicating their taste?

The sampling of the interview partners was conducted purposefully to gather a contrastive sample of lower and middle class Pentecostals. ${ }^{21}$ The focus of the sampling strategy was particularly on the middle class: out of a total of

18 The term "middle class churches" refers to churches that recruit a significant proportion of middle class Pentecostals.

19 The names of the interviewed pastors haven been changed.

20 For qualitative interviews, see Diekmann 1995: 443-455; Flick 2002: 117-145; Knoblauch 2003: 122-134; Patton 1990: 277-359.

21 For purposeful sampling, see Patton 1990: 169-183. 
44 interviews 30 interviews were conducted with middle class Pentecostals and 14 with lower class Pentecostals. For the sample of the middle class, I sought Pentecostals who had attained or were to attain higher education degrees (university or tertiary) and had a household income per capita above the Argentinean average. For the lower class group, I searched for Pentecostals that had significantly lower education degrees than finished secondary school and perceived lower household incomes per capita than my interviewees from middle class group. In order to avoid any effect of the religious style of a specific church on the results, the 44 interviewees were sampled from 22 different Pentecostal churches. ${ }^{22}$

Interviews were conducted with an interview guide approach. ${ }^{23}$ The semistructured interviews allowed for a high flexibility while guaranteeing, at the same time, the comparability of interviews due to a similar interview design. Interviews were audio-taped and lasted in the majority of cases between two and three hours. The main areas of the interview referred to the biography, religious choice (current, past and potential church affiliations), social background, religious upbringing, and religious preferences of the interviewee. Moreover, interviews included short video sequences which showed religious practices of other Pentecostal churches. After watching the video sequences, interviewees were asked about their opinion. This method allowed interviewees to communicate likes and dislikes with regard to specific styles of Pentecostalism. Thus, middle class Pentecostals often used the impressions from the video in order to draw boundaries in opposition to particular attributes of Pentecostalism. The interviews were analyzed with the software program Atlas.ti. After analysing and comparing the tastes of the lower and middle class interviewees, I wrote a case study summarizing the preferences of each group. These case studies enabled me to identify the cultural characteristics that middle class Pentecostals employ to draw boundaries. In order to ensure the anonymity of my interview partners, their names have been changed in this study.

In total, the empirical research explored the relationship between the middle class and Pentecostalism on the level of church styles and religious tastes. Although the research on the meso and micro level were conducted and analyzed separately, the results from both levels of research turned out to be highly congruent and are, therefore, portrayed together in this study. The comparison of the tastes and styles of Pentecostals from different social backgrounds was

22 Since the taste of an individual may be influenced by the style of the church to which he is affiliated, interviewees had to be sampled from a variety of churches.

23 Patton 1990: 283-284. 
carried out with regard to different aspects of Pentecostal practice. Thus, tastes and styles were compared, for instance, with regard to the organization, infrastructure, and status of churches, as well as their music, spiritual practices, and sermons.

\subsection{Remaining Limitations of the Study}

The study faces several restrictions inherent to qualitative research. Although a mixture of methods and different data sources are employed, the scope of the study is highly limited: as in every qualitative research project, the question of whether the studied cases can be generalized to the whole population - in this case middle class Pentecostals in Argentina - remains an open one. Conclusions from this research will have to be drawn with caution. Yet, as stated already above, the project is conceptualized as an explorative study. As such, it may create a data basis for further - potentially quantitative - research about middle class Pentecostals in Argentina or in other regions. ${ }^{24}$

Another potential problem of qualitative research lies in the subjectivity of the observer. ${ }^{25}$ The observer's background may bias the research. ${ }^{26}$ Rephrasing this problem in terms of the boundary work approach, one has to acknowledge the ubiquity of symbolic boundaries. Actors draw boundaries with which they classify their environment and distinguish between valuable and less valuable things, practices, attitudes, and people. ${ }^{27}$ The tendency to draw boundaries concerns also religion: even when abstaining from regular religious practice, individuals communicate their opinions, likes, and dislikes

24 Another limitation of the study is its emphasis on middle class: the study explores the boundary work of middle class Pentecostals. At the same time it widely disregards the boundary work of lower class Pentecostals. Disregarding the lower class boundary work does not mean that lower class Pentecostals do not draw boundaries. In fact, they draw boundaries and seek distinction from other actors. Yet, this study concentrates on Argentina's middle class Pentecostals.

25 Knoblauch 2003: 162, 169.

26 Among other factors, my European background ran the risk of directly influencing the research through my perspective and indirectly through its impact on my interview partners.

27 Particularly the middle class background of academics can have an impact on their research when dealing with different social classes. Diane Reay states: "The challenge for all theorists of class is how to problematise the middle-class perspective in which academics are inevitably caught up." (Reay 2005b: 143) See also Reay 1998: 266; 2005b: 141,143; Skeggs 1997: 167 . 
concerning religion, describing, for instance, religious fundamentalists as mad, stating doubt about the contraception policies of the Vatican, or showing sympathy with the Taizé movement. Also researchers of religion are not free of religious preferences. ${ }^{28}$ They may prefer some types of religious practice over others and feel disdain for some expressions of religion, which may influence their work. ${ }^{29}$ While exploring Pentecostalism in Argentina, I felt sympathy for some of the religious practices that I observed and for others less. Being relatively conscious about my personal religious preferences, I hope to have limited any effect of my personal religious taste on this study. In addition, I sought to prevent the general impact of my subjective preferences and perceptions as far as possible by triangulation, communicative validation, and the orientation on criteria for good research.

\subsection{Summary}

This chapter described the methodological approach of the research. The empirical study was conceptualized as an explorative research project and was conducted on three empirical levels: macro-, meso-, and micro-level. The macro-level refers to the context of middle class Pentecostalism in Argentina and is based on an analysis of the existing literature about social class, religion in general, and Pentecostalism in particular. The actual empirical study was conducted on the meso- and micro-level. The meso-level explores the religious styles of different Pentecostal churches through ethnographic observations and interviews with pastors. The micro-level explores the tastes of Pentecostals through interviews with Pentecostals from different social backgrounds. The empirical data gathered through the meso- and micro-level research allows for determining specific religious styles and tastes among middle class Pentecostals.

28 See, for instance, Bourdieu 1987.

29 McCloud, for instance, states: "Scholars routinely and often explicitly deemed the religions of minorities, the poor, and the indigenous as inferior." (McCloud 2007b: 844) Thus, some scholars charge each other with showing disdain against lower class religious movements and thereby dedicate themselves to symbolic boundary work in academia. One example is B. Martin (2006) who charges Lehmann (1996) with depreciating Pentecostalism as a "bad taste". 